\title{
Who to Refer to a Behavioral Insomnia Clinic? - Recommendations Based on Treatment Rationale and Response Prediction
}

\author{
Joshua H. Cho ${ }^{1}$. Stephanie Kremer ${ }^{1}$ Jeffrey Young ${ }^{1}$ \\ Accepted: 3 November 2021 / Published online: 17 November 2021 \\ (c) The Author(s), under exclusive licence to Springer Nature Switzerland AG 2022
}

\begin{abstract}
Purpose of Review Response to cognitive-behavioral therapy for insomnia (CBT-I) is variable across individuals, and specialty insomnia clinics that provide CBT-I are few. To personalize insomnia treatments and maximize the cost-effectiveness of CBT-I, this paper reviews the conceptual model and content of CBT-I and the predictors of adherence/response to CBT-I as the basis for understanding who is most likely to benefit from CBT-I.

Recent Findings Specific patient-related attributes that predict benefit from CBT-I include (1) presence of maladaptive behaviors that serve as perpetuating factors of insomnia; (2) greater motivation to pursue therapy and higher treatment expectancies regarding CBT-I; (3) reduced use of hypnotics; (4) longer sleep duration; and (5) adequately treated psychiatric comorbidities. Summary People presenting with chronic insomnia and these attributes may warrant prioritization in referral to behavioral insomnia clinics. Conversely, those who do not have such favorable characteristics may require interventions that address modifiable factors associated with poor adherence/response to CBT-I.
\end{abstract}

Keywords Chronic insomnia $\cdot$ Cognitive-behavioral therapy for insomnia $\cdot$ Predictors of treatment response $\cdot$ Predictors of adherence

\section{Introduction}

Insomnia disorder is defined as difficulty initiating sleep, difficulty maintaining sleep, or early morning awakening despite adequate opportunity for sleep with clinically significant distress or impairments in functioning, a frequency of 3 or more nights per week, and a duration of 3 months or longer (Diagnostic and Statistical Manual of Mental Disorders, 5th Edition: DSM-5) [1]. Insomnia is a common and costly condition. About $30 \%$ of the general population have complaints of sleep disruption, and at least $10 \%$

This article is part of the Topical Collection on Sleep and Neurological Conditions

Joshua H. Cho

hjcho@mednet.ucla.edu

1 UCLA Insomnia Clinic, Cousins Center for Psychoneuroimmunology, Department of Psychiatry and Biobehavioral Sciences, David Geffen School of Medicine at UCLA, University of California Los Angeles, 300 UCLA Medical Plaza, Suite 3200A, Los Angeles, CA 90095, USA have sleep complaints and associated impairment to meet the diagnosis of insomnia disorder, which by definition is chronic ( $\geq 3$ months) [2]. Insomnia costs the US workforce $\$ 63.2$ billion a year in lost productivity [3]. Furthermore, insomnia increases the risks of psychiatric conditions such as depression and medical diseases including inflammatory, metabolic, cardiovascular, and neurocognitive disorders [4]. However, insomnia often remains untreated or inappropriately treated.

Behavioral treatments such as cognitive-behavioral therapy for insomnia (CBT-I) have been consistently and widely demonstrated to be an efficacious treatment of insomnia [5]. Studies have demonstrated the efficacy of CBT-I in the treatment of insomnia that is frequently comorbid or occurring in the context of psychiatric and medical disorders, as well as encouraging findings that CBT-I may additionally improve other comorbid symptoms in these disorders [6, 7]. Recent research suggests that CBT-I is a promising treatment for insomnia and other health-related outcomes in people experiencing depression, cancer, mild cognitive impairment, traumatic brain injury, multiple sclerosis, headaches, chronic pain, and menopause [8-19]. With the established short- and 
long-term efficacy, CBT-I is actually the standard and the first-line treatment of chronic insomnia as recommended by, respectively, the American Academy of Sleep Medicine and the American College of Physicians [20, 21]. Despite these institutional recommendations, in a survey of physicians in two US university hospitals, very few people with insomnia were referred for treatment with CBT-I [22]. This was in line with another study that found $88 \%$ of British general practitioners provide people affected with insomnia with "sleep hygiene" advice while they often perceive this to be insufficient and these individuals suffering from insomnia are rarely offered CBT-I [23]. In short, although there is robust empirical evidence for CBT-I, the practice of specific referral of people with insomnia to CBT-I is severely limited. The reasons for this limitation may include (1) the suboptimal awareness of CBT-I by physicians regarding its rationale and indication [22, 24] and (2) the scarcity of specialty services that provide CBT-I given the lack of trained clinicians [24, 25].

The purpose of this paper is to review the theoretical rationale behind CBT-I and the predictors of adherence and response to CBT-I, which will be the basis for understanding who is most likely to benefit from CBT-I. This review will aid referring physicians increase their awareness of CBT-I and recognize patient-related factors associated with greater response to behavior modification. Given the scarcity of behavioral insomnia clinics and the often-difficult access to such specialty clinics, understanding the indication of CBT-I and the clinical characteristics of people with insomnia most appropriate for CBT-I would be particularly useful at the time of initiation of the referral [26]. Physicians would be able to match insomnia sufferers with the most suitable treatment, which would optimize limited resources of specialty behavioral insomnia clinics and, at the same time, enhance treatment outcome and patient satisfaction [26]. Of note, as in any behavior modification interventions and especially due to the seemingly counterintuitive logic of CBT-I (e.g., restricting time in bed and getting out of bed if unable to sleep), adherence is intimately related to the success and effectiveness of CBT-I. Indeed, there has been consistent evidence that greater adherence predicts better treatment outcome of CBT-I [27•, 28, 29]. This review will highlight patient characteristics associated with favorable response and adherence to CBT-I as an approach to understanding the optimal CBT-I referral strategy.

\section{Behavioral Insomnia Clinics}

Behavioral insomnia clinics may exist as a separate service in a close collaboration with or as an affiliated service within a sleep disorders center. In either case, behavioral insomnia clinics provide diagnostic assessment and evidence-based behavioral treatment of insomnia, typically administered by an interdisciplinary team of providers. The goal of the clinic is to improve sleep duration and quality, as well as alleviate distress related to insomnia, with safe and effective behavioral health treatments. Most often these evidence-based treatments are implemented while reducing and alleviating the use of pharmacological agents with the aim of diminishing the reliance on hypnotics [21]. An intervention with a focus on decreasing or eliminating the reliance on hypnotics is of fundamental importance not only due to the risk of adverse consequences associated with these agents but also because chronic hypnotic use predicts poor response to behavioral insomnia management $[26,30 \bullet \bullet, 31,32]$. Among these behavioral treatments, CBT-I is a first-line treatment with proven short- and longterm efficacy as described above [20, 21]. Other mind-body approaches with an increasing evidence base such as mindfulness-based interventions may also be utilized in lieu of or in addition to CBT-I [33, 34•, 35, 36].

Upon referral to a behavioral insomnia clinic, a thorough clinical assessment is conducted to determine the appropriateness of these treatments for the patient. An emphasis is placed on a comprehensive sleep history, with a focus on the frequency and duration of sleep complaints, activities leading up to sleep, sleep duration and schedule, activities pursued when insomnia occurs, sleep environment (temperature, light exposure, noise levels), interventions pursued previously, likely precipitating events, and expectations. Comorbid conditions should be identified that may contribute to sleep difficulties or that may interfere with effective implementation of the interventions. Screening or diagnostic tools could be used to supplement the clinical assessment such as sleep diary and sleep questionnaires (e.g., the Insomnia Severity Index [37] and the Sleep Condition Indicator [38]).

The patient should ideally be involved in a collaborative shared decision-making process after the initial assessment to identify and deploy the most appropriate intervention(s), as patient-centered selection of treatment modality based on their own preference and active participation improve adherence and outcomes [39, 40]. Behavioral treatments such as CBT-I and mindfulness-based therapies are structured interventions requiring a high level of patient engagement outside of sessions; thus, early engagement is critical. CBT-I can be utilized in individual or group format. The typical range in number of sessions for CBT-I is 4 to 8 sessions with optional booster sessions over time as needed to reinforce treatment gains [41].

\section{Theoretical Rationale of CBT-I: Spielman Model of Insomnia}

The Spielman model of insomnia [42] is a mainstay of insomnia conceptualization and is commonly utilized in clinic reports as a template for documentation and treatment 
planning. The model is also very straightforward and can be easily presented to patients in session as a guide to understanding how insomnia develops and is maintained, as well as appreciating treatment rationale. This conceptual model is also an important element in understanding who would be an appropriate candidate and likely to benefit from CBT-I [43]. Often referred to as the " $3 \mathrm{P}$ " model, the Spielman model is constructed of 3 factors that explain the initiation and maintenance of insomnia; these factors, in temporal order, are Predisposing, Precipitating, and Perpetuating. Predisposing factors include any medical, sleep, or psychiatric disorders or prevailing life circumstances that precede the episode of insomnia and confer the substrate of vulnerability upon which the episode of insomnia is built. Specific examples include chronic pain, sleep apnea, anxiety, depression, and family history of insomnia. As Spielman has established, predisposing factors are by definition not sufficient to provoke an episode of insomnia. As such, a precipitating event must occur in the context of that underlying vulnerability. Common precipitants such as job stress, relationship concerns, hospitalizations, episodes of pain, and exacerbations of psychiatric disorders act in combination with predisposing factors to produce an episode of insomnia in its initial or acute form. The COVID-19 Pandemic is a recent precipitating factor that emerged in the context of "coronasomnia" or "Covidsomnia" [44].

It is rare, however, to find cases of insomnia presenting at clinic that are fueled by predisposing and precipitating factors alone (i.e., acute form). Perpetuating factors (the third "P") tend to follow closely behind because they provide an emotionally satisfying, yet ultimately counterproductive, sense of control over lost sleep and associated anxiety. Perpetuating factors such as extending sleep opportunity to make up for lost sleep (in bed early, out of bed late, napping) can lead to multiple instances of trying to initiate sleep at times when sleep drive may be low and circadian position may be suboptimal. This leaves the patient in bed for long periods of time awake, frustrated, and "trying to sleep" all the while transforming the bedroom, once peaceful and inviting of sleep, into a stimulus for wakefulness and distress. It is these perpetuating factors that maintain the insomnia long after the influence of the precipitating event has faded, and it is these perpetuating factors that become the primary targets of treatment in the clinic. Thus, the presence of such perpetuating factors as extending sleep opportunity (going to bed early, sleeping in, and prolonged napping) and engaging in non-sleep behaviors in bed characterizes people who are most likely to respond to CBT-I [43].

\section{Key Interventions in CBT-I}

Stimulus control therapy (SCT) is a therapeutic extension of the Spielman model discussed above and is a fundamental part of the CBT-I protocol [45]. The technique has essentially two related elements-taking sleeplessness out of the bedroom and limiting bedroom activities to sleep and sleep-related activity (sexual activity is the exception). As part of this protocol, patients are instructed to exit the bed and bedroom after sensing that they have been lying in bed awake for more than roughly $20 \mathrm{~min}$ or at the first sign of frustration, anger, or increasing anxiety while in bed (clock watching to gauge time is not allowed). Another part of stimulus control is eliminating non-sleep-related behaviors from the bedroom both around bedtime and during the day (e.g., watching television, video games, working on a laptop, heated family, or work conversations). Here, we are looking to establish a very clear conditioning history for the bedroom such that the bedroom evokes a release of psychological and physiological tension and is further associated with the reliable initiation of sleep. If a patient spends quite a bit of time in the bedroom working, having heated conversations, or playing video games, then the stimulus value of the bedroom to evoke relaxation and sleep is degraded such that entering the bedroom could evoke associations to any of those activities.

Another fundamental part of CBT-I is sleep restriction therapy (SRT) [46]. SRT limits the amount of time a patient may spend in bed to the average number of hours of nightly sleep time as indicated by sleep diaries (baseline data is recorded over a 1- to 2-week period). For example, if a patient's sleep diary indicates that over the preceding 2 -week period the average total sleep time (TST) is $6 \mathrm{~h}$, then treatment begins with the patient's sleep opportunity limited to $6 \mathrm{~h}$. In this protocol, the patient is also asked to keep track of their sleep efficiency (SE\%), which is defined as Amount of Sleep Obtained divided by the Amount of Sleep Opportunity multiplied by 100 to yield a percentage. If the patient reports that they had spent $10 \mathrm{~h}$ in bed only to obtain $6 \mathrm{~h}$ of sleep then their SE\% is $6 / 10 \times 100=60 \%$. Once these calculations are made, treatment begins with deciding on a time-out-of-bed (TOB) that works well with the patient's daytime demands and circadian rhythm and can be implemented 7 days per week. In this case, let us say that the patient picks 6 am as their TOB. Given that we know that this patient's TST is $6 \mathrm{~h}$ and their TOB is now 6 $\mathrm{am}$, it follows that their new and prescribed bedtime is 12 am. Clinically, we expect that the patient will have a rather elevated sleep drive at $12 \mathrm{am}$, which will not only help ensure that sleep will come quickly but will improve sleep continuity and quality. A sleep diary is kept and evaluated once per week to see how sleep efficiency has improved. 
If the average sleep efficiency for that week is above $90 \%$ ( $85 \%$ for older adults), then time in bed (TIB) is advanced by 15 min yielding more sleep opportunity. This evaluation of sleep efficiency continues week by week, and as long as sleep efficiencies remain high, at roughly $90 \%$, then TIB continues to advance by $15 \mathrm{~min}$. No change in TIB is made if sleep efficiency is at roughly $85 \%$, and TIB is delayed by $15 \mathrm{~min}$ if sleep efficiency is below about $80 \%$.

In addition to the behavioral interventions, cognitive therapy is also a critical and efficacious element of CBT-I [47]. Cognitive therapy targets counterproductive or false beliefs about sleep and sleep loss. Very often, patients will present with various worries that only serve to increase agitation at night as well as during the day. Common presenting concerns include "you can't function unless you get eight hours of sleep per night," "people who sleep well never wake in the middle of the night," and "if I don't sleep well tonight, I will not perform well at work tomorrow and I will lose my job." Cognitive therapy addresses these issues by providing accurate information on how sleep works and by challenging the veracity of catastrophic thoughts about the consequences of sleep loss.

Among the most important cognitive and behavioral elements to address is sleep effort. Sleep effort is anything the patient does with the intention of that activity leading to sleep. Thinking this way places a heavy burden on the patient to figure out how to do something that they cannot possibly do; that is, put themselves to sleep. Many patients come to the clinic utterly demoralized after unsuccessfully trying various forms of meditation and relaxation in an effort to fall asleep. We teach them that no amount of effort can get them to sleep; in fact, the opposite effect-increased arousal-is almost always the case. Relaxation ensues once the patient accepts that chasing after sleep cannot work and that sleep will simply come to them as it always has and always will without any need for their direct effort or input. Yes, meditation and relaxation techniques are very useful and can reduce psychological and physiological arousal but should be done for only its own merits and not as a direct pathway to sleep.

\section{What to Expect During CBT-I Treatment}

CBT-I is a very structured psychotherapeutic intervention typically deployed over a 6- to 8-week period [48]. The patient and clinician meet in 1-week intervals and each session is dedicated to developing a specific therapeutic skill in addition to providing psychoeducation about sleep. Skills would include relaxation training to help reduce arousal paired with education on how the sleep effort mindset can undermine their aim to relax and initiate sleep. Fundamental to CBT-I is the use of stimulus control and sleep restriction. Patients are given specific instructions on how to use these techniques as well as education on the rationale behind their use. Each week the clinician will check in to see how the patient is doing overall with the treatment and to troubleshoot any issues with compliance. Additionally, the sleep diary is reviewed to evaluate sleep patterns and to determine that week's sleep efficiency so that a decision can be made as to whether sleep opportunity should be increased, decreased, or stay the same.

\section{Predictors of Response to CBT-I}

Another approach to understanding who would most likely benefit from CBT-I is examining the predictors of treatment response. The research on this particular topic is still limited and somewhat inconsistent as the findings have been largely divergent, even on the same variable such as age [26, 30••, 31, 49, 50]. Here, we describe more consistent findings regarding the prediction of treatment response to CBT-I. First, the use of hypnotic medications has been consistently associated with suboptimal response to CBT-I in different populations of people with insomnia [26, 30••, 31, 32], although a non-significant association has also been reported [50]. Development of tolerance to benzodiazepine hypnotics, reliance on medications, and reduced learning efficiency derived from cognitive effects of hypnotics may explain this finding $[26,51,52]$. Second, a short sleep duration has been shown to predict a poor response to CBT-I. People affected by insomnia with objective short sleep duration (i.e., $<6 \mathrm{~h}$ ) measured using wrist actigraphy (an accelerometer) or polysomnography were significantly less likely to respond to CBT-I and brief behavioral treatment of insomnia (BBTI), a variant of CBT-I delivered over 4 weekly sessions

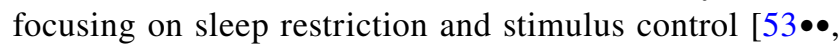
54]. Similarly, long total sleep time was the only significant predictor of response to manual-guided CBT-I delivered by non-expert primary-care personnel, a low-end treatment

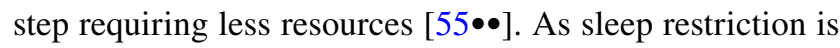
one of the core components of CBT-I, short sleep duration may add a challenge to the implementation of this intervention and may induce deleterious consequences in patients who require to be alert at work at least at the initial stage of this intervention. Although the overall evidence supports the idea of short sleep duration being a predictor of poor response, it should be noted that recent studies have also found an opposite trend, that is, short sleep duration predicting a boosted response to CBT-I [56, 57]. Third, treatment expectancies predict response to CBT-I. Higher initial levels of expectation regarding the treatment effectiveness predicted subjective sleep improvements following CBT-I $[29,50]$. Lastly, the presence of psychopathology such as 
depression and anxiety generally predicts less favorable response to CBT-I. Psychiatric comorbidity has been shown to predict poorer treatment response $[49,58 \bullet \bullet$, although there have been somewhat divergent and inconsistent findings as well $[50,54]$.

\section{Predictors of Adherence to CBT-I}

According to the World Health Organization, adherence is defined as "the extent to which a person's behavior-taking medication, following a diet, and/or executing lifestyle changes - corresponds with agreed recommendations from a health care provider" [59]. As mentioned in the introduction, adherence has been consistently shown to predict the outcome of CBT-I [27•, 28, 29]. Thus, another approach to identifying suitable candidates for CBT-I and improving its indication is examining predictors of adherence to CBT-I. First, better adherence has been predicted by psychological factors related to CBT-I itself such as greater motivation for treatment and higher treatment expectancies [40, 41, 60]. Second, psychiatric comorbidities consistently predict poor adherence to CBT-I. Symptoms and disorders of depression and anxiety in people with insomnia have been associated with less attendance of CBT-I sessions and less observance of CBT-I recommendations [28, 41, 61, 62•, 63]. Third, short sleep duration has been associated with poor adherence [61, 64]. A recent study has nevertheless found a longer total sleep time to predict early dropout from internet-based self-help CBT-I [63]. However, in studies of therapist-conducted CBT-I in both individual and group formats, short sleep duration predicted poor adherence [61, 64]. Individuals suffering from insomnia with short sleep duration may be less amenable to sleep restriction, thus less likely to adhere to CBT-I.

\section{Conclusions}

Who would most benefit from CBT-I? Who would be most suitable for a referral to CBT-I? Although the empirical research evidence on the predictors of response and adherence to CBT-I is still limited and somewhat inconsistent, based on the conceptual model of CBT-I and the convergence of these two groups of predictors, we propose the following recommendations regarding the profile of people with insomnia who are most likely to benefit from CBT-I (Table 1):

(1) presence of maladaptive behaviors that serve as perpetuating factors of insomnia (e.g., going to bed early, sleeping in, napping, and engaging in non-sleep behaviors in bed)

(2) greater motivation and higher treatment expectancies regarding CBT-I

(3) reduced use of hypnotic medications

(4) longer sleep duration

(5) adequately treated psychiatric comorbidities or absence thereof

Given the limited availability of specialty insomnia clinics that offer behavioral treatments such as CBT-I, patients suffering from insomnia with the aforementioned profile may warrant a prioritization in referral to specialty insomnia clinics. Conversely, patients who do not have such favorable

Table 1 Clinical characteristics of people with insomnia who are most likely to benefit from cognitive-behavioral therapy for insomnia (CBT-I)

\begin{tabular}{|c|c|c|}
\hline Favorable clinical characteristics & Based on & For patients without favorable characteristics \\
\hline $\begin{array}{l}\text { Presence of maladaptive behaviors that serve } \\
\text { as perpetuating factors of insomnia (e.g., } \\
\text { going to bed early, sleeping in, napping, and } \\
\text { engaging in non-sleep behaviors in bed) }\end{array}$ & Conceptual model of CBT-I & $\begin{array}{l}\text { Consider alternative treatments, e.g., mindful- } \\
\text { ness-based therapies or pharmacotherapy }\end{array}$ \\
\hline $\begin{array}{l}\text { Greater motivation and higher treatment expec- } \\
\text { tancies regarding CBT-I }\end{array}$ & $\begin{array}{l}\text { Prediction of adherence and treatment } \\
\text { response }\end{array}$ & $\begin{array}{l}\text { Provide information and conduct motivational } \\
\text { interviewing prior to or at the intake of } \\
\text { CBT-I to boost motivation for the treatment }\end{array}$ \\
\hline Reduced use of hypnotic medications & Prediction of treatment response & $\begin{array}{l}\text { Reduce the use of hypnotic medications or at } \\
\text { least inquire about the patient's willingness } \\
\text { to taper off such medications prior to or dur- } \\
\text { ing the early stage of CBT-I }\end{array}$ \\
\hline Longer sleep duration & $\begin{array}{l}\text { Prediction of adherence and treatment } \\
\text { response }\end{array}$ & $\begin{array}{l}\text { Consider a time-limited treatment with a hyp- } \\
\text { notic medication prior to or during the early } \\
\text { stage of CBT-I to extend total sleep time } \\
\text { (and taper off later) }\end{array}$ \\
\hline Adequately treated psychiatric comorbidities & $\begin{array}{l}\text { Prediction of adherence and treatment } \\
\text { response }\end{array}$ & $\begin{array}{l}\text { Treat comorbidities prior to CBT-I and/or } \\
\text { incorporate therapeutic components that } \\
\text { address depression/anxiety to CBT-I }\end{array}$ \\
\hline
\end{tabular}


characteristics may require some interventions that address those modifiable risk factors associated with poor adherence and less robust response to CBT-I. Although the evidence on such modifiable factors is essentially observational and the actual modification of such factors has not been empirically tested, clinicians that manage insomnia routinely experience the benefit of treating those modifiable factors prior to or during the early stage of CBT-I. For example, patients could be encouraged to reduce the use of hypnotic medications or at least could be inquired about the willingness to taper off such medications. This action may be particularly important as a large proportion of patients with insomnia take hypnotic medications. Ideally, psychiatric comorbidities such as depression and anxiety should be adequately treated prior to initiating CBT-I, although the presence of untreated sleep disturbances may hinder full remission of co-occurring psychiatric disorders. As an alternative or a subsequent approach to this, therapeutic components that also address depression and/or anxiety, such as behavioral activation, could be incorporated to CBT-I [65]. Patients with limited knowledge about and motivation for CBT-I may be provided information and participate in motivational interviewing to boost their motivation for the treatment. Patients may initially refuse or be hesitant to engage in CBT-I for a variety of reasons. Some may not be able to or reluctant to commit the time or financial resources to attending the sessions needed. Educating people on the time-limited nature and enduring benefits of CBT-I in comparison to other interventions (e.g., hypnotic medications) may improve engagement. Many people may have never participated in psychotherapy and be unfamiliar with psychological interventions and/or concerned about associated stigma. Addressing these concerns with clear information on the structure and nature of the intervention, the prevalence of insomnia, and the enduring nature of treatment may be beneficial. Patients with short sleep duration may be offered a time-limited treatment with a hypnotic medication prior to or during the early stage of CBT-I to extend total sleep time (followed by tapering off afterwards). Indeed, a randomized controlled trial demonstrated that the addition of a hypnotic medication such as zolpidem to CBT-I produced added benefits during the acute 6-week phase of the therapy, but better long-term outcomes were achieved when zolpidem was discontinued after the initial 6-week phase [66]. Alternatively, patients who are less likely to benefit from CBT-I may be offered pharmacotherapy or a different modality of evidence-based behavioral insomnia treatments such as mindfulness-based interventions. The latter has a demonstrated efficacy and a favorable profile of acceptability and adherence by patients [34•].

Cognitive-behavioral therapy for insomnia (CBT-I) is widely acknowledged as the first-line treatment for insomnia. However, because it is a treatment that essentially consists in behavior modification and cognitive restructuring,
CBT-I has inherent limitations. Adjunct interventions that overcome such limitations of CBT-I would be of a paramount importance in clinical practice. This issue will review behavioral, pharmacological, and other interventions that may complement and/or serve as an alternative option to CBT-I.

CBT-I is the first-line treatment of insomnia with demonstrated short- and long-term efficacy. However, because it is a treatment that essentially consists in behavior modification and cognitive restructuring, not all patients embrace this modality and there is a sizable variability in treatment response across individuals. Furthermore, due to the lack of trained behavioral therapists, the availability of CBT-I is limited. Therefore, to maximize the cost-effectiveness of CBT-I and to personalize insomnia treatments according to patient characteristics, identifying who is most likely to benefit from different insomnia treatments is essential and requires further research.

\section{Compliance with Ethical Standards}

Conflict of Interest None.

Human and Animal Rights This article does not contain any studies with human or animal subjects performed by any of the authors.

\section{References}

Papers of particular interest, published recently, have been highlighted as:

- Of importance

$\bullet$ Of major importance

1. Diagnostic and statistical manual of mental disorders: DSM-5 $5^{\mathrm{TM}}$, 5th ed. Arlington: American Psychiatric Publishing, Inc.; 2013.

2. National Institutes of H. National Institutes of Health State of the Science Conference statement on Manifestations and Management of Chronic Insomnia in Adults, June 13-15, 2005. Sleep. 2005;28(9):1049-57. https://doi.org/10.1093/sleep/28.9.1049.

3. Kessler RC, Berglund PA, Coulouvrat C, Hajak G, Roth $\mathrm{T}$, Shahly V, et al. Insomnia and the performance of US workers: results from the America insomnia survey. Sleep. 2011;34(9):1161-71. https://doi.org/10.5665/SLEEP.1230.

4. Irwin MR. Why sleep is important for health: a psychoneuroimmunology perspective. Annu Rev Psychol. 2015;66:143-72. https://doi.org/10.1146/annurev-psych-010213-115205.

5. Trauer JM, Qian MY, Doyle JS, Rajaratnam SM, Cunnington D. Cognitive behavioral therapy for chronic insomnia: a systematic review and meta-analysis. Ann Intern Med. 2015;163(3):191204. https://doi.org/10.7326/M14-2841.

6. Wu JQ, Appleman ER, Salazar RD, Ong JC. Cognitive behavioral therapy for insomnia comorbid with psychiatric and medical conditions: a meta-analysis. JAMA Intern Med. 2015;175(9):1461-72.

7. Smith MT, Huang MI, Manber R. Cognitive behavior therapy for chronic insomnia occurring within the context of medical 
and psychiatric disorders. Clin Psychol Rev. 2005;25(5):55992. https://doi.org/10.1016/j.cpr.2005.04.004.

8. Kalmbach DA, Cheng P, Arnedt JT, Anderson JR, Roth T, Fellman-Couture C, et al. Treating insomnia improves depression, maladaptive thinking, and hyperarousal in postmenopausal women: comparing cognitive-behavioral therapy for insomnia (CBTI), sleep restriction therapy, and sleep hygiene education. Sleep Med. 2019;55:124-34.

9. Selvanathan J, Pham C, Nagappa M, Peng PW, Englesakis M, Espie CA, et al. Cognitive behavioral therapy for insomnia in patients with chronic pain-a systematic review and metaanalysis of randomized controlled trials. Sleep Med Rev. 2021;60:101460. https://doi.org/10.1016/j.smrv.2021.101460.

10 Smitherman TA, Kuka AJ, Calhoun AH, Walters ABP, DavisMartin RE, Ambrose CE, et al. Cognitive-behavioral therapy for insomnia to reduce chronic migraine: a sequential Bayesian analysis. Headache. 2018;58(7):1052-9.

11. Smitherman TA, Walters AB, Davis RE, Ambrose CE, Roland M, Houle TT, et al. Randomized controlled pilot trial of behavioral insomnia treatment for chronic migraine with comorbid insomnia. Headache. 2016;56(2):276-91.

12. Siengsukon CF, Alshehri M, Williams C, Drerup M, Lynch S. Feasibility and treatment effect of cognitive behavioral therapy for insomnia in individuals with multiple sclerosis: A pilot randomized controlled trial. Mult Scler Relat Disord. 2020;40:101958.

13. Ludwig R, Vaduvathiriyan P, Siengsukon C. Does cognitivebehavioural therapy improve sleep outcomes in individuals with traumatic brain injury: a scoping review. Brain Inj. 2020;34(12):1569-78.

14. Cassidy-Eagle E, Siebern A, Unti L, Glassman J, O'Hara R. Neuropsychological functioning in older adults with mild cognitive impairment and insomnia randomized to CBT-I or control group. Clin Gerontol. 2018;41(2):136-44.

15. Johnson JA, Rash JA, Campbell TS, Savard J, Gehrman PR, Perlis M, et al. A systematic review and meta-analysis of randomized controlled trials of cognitive behavior therapy for insomnia (CBT-I) in cancer survivors. Sleep Med Rev. 2016;27:20-8.

16. Ma Y, Hall DL, Ngo LH, Liu Q, Bain PA, Yeh GY. Efficacy of cognitive behavioral therapy for insomnia in breast cancer: a meta-analysis. Sleep Med Rev. 2021;55:101376. https://doi.org/ 10.1016/j.smrv.2020.101376.

17. Peoples AR, Garland SN, Pigeon WR, Perlis ML, Wolf JR, Heffner KL, et al. Cognitive behavioral therapy for insomnia reduces depression in cancer survivors. J Clin Sleep Med. 2019;15(1):129-37.

18 Carney CE, Edinger JD, Kuchibhatla M, Lachowski AM, Bogouslavsky O, Krystal AD, et al. Cognitive behavioral insomnia therapy for those with insomnia and depression: a randomized controlled clinical trial. Sleep. 2017;40(4):zsx019.

19. Cunningham JE, Shapiro CM. Cognitive behavioural therapy for insomnia (CBT-I) to treat depression: a systematic review. J Psychosom Res. 2018;106:1-12.

20 Morgenthaler T, Kramer M, Alessi C, Friedman L, Boehlecke $\mathrm{B}$, Brown T, et al. Practice parameters for the psychological and behavioral treatment of insomnia: an update. An american academy of sleep medicine report. Sleep. 2006;29(11):1415-9. https://doi.org/10.1093/sleep/29.11.1415.

21. Qaseem A, Kansagara D, Forciea MA, Cooke M, Denberg TD, Clinical Guidelines Committee of the American College of P. Management of chronic insomnia disorder in adults: a clinical practice guideline from the American College of Physicians. Ann Intern Med. 2016;165(2):125-33. https://doi.org/10.7326/ M15-2175.

22. Conroy DA, Ebben MR. Referral practices for cognitive behavioral therapy for insomnia: a survey study. Behav Neurol. 2015;2015:819402. https://doi.org/10.1155/2015/819402.
23. Everitt H, McDermott L, Leydon G, Yules H, Baldwin D, Little P. GPs' management strategies for patients with insomnia: a survey and qualitative interview study. $\mathrm{Br} \mathrm{J}$ Gen Pract. 2014;64(619):e112-9. https://doi.org/10.3399/bjgp14X677176.

24. Koffel E, Bramoweth AD, Ulmer CS. Increasing access to and utilization of cognitive behavioral therapy for insomnia (CBTI): a narrative review. J Gen Intern Med. 2018;33(6):955-62. https://doi.org/10.1007/s11606-018-4390-1.

25. Espie CA. "Stepped care": a health technology solution for delivering cognitive behavioral therapy as a first line insomnia treatment. Sleep. 2009;32(12):1549-58.

26. Gagné A, Morin CM. Predicting treatment response in older adults with insomnia. J Clin Geropsychol. 2001;7(2):131-43.

27. Dong L, Soehner AM, Belanger L, Morin CM, Harvey AG. Treatment agreement, adherence, and outcome in cognitive behavioral treatments for insomnia. J Consult Clin Psychol. 2018;86(3):294-9. https://doi.org/10.1037/ccp0000269. Greater adherence to CBT-I predicted better treatment outcome.

28. Vincent NK, Hameed H. Relation between adherence and outcome in the group treatment of insomnia. Behav Sleep Med. 2003;1(3):125-39. https://doi.org/10.1207/S15402010B SM0103_1.

29. Tremblay V, Savard J, Ivers H. Predictors of the effect of cognitive behavioral therapy for chronic insomnia comorbid with breast cancer. J Consult Clin Psychol. 2009;77(4):742-50. https://doi.org/10.1037/a0015492.

30.• El-Solh AA, O’Brien N, Akinnusi M, Patel S, Vanguru L, Wijewardena C. Predictors of cognitive behavioral therapy outcomes for insomnia in veterans with post-traumatic stress disorder. Sleep Breath. 2019;23(2):635-43. https://doi.org/10. 1007/s11325-019-01840-4.Hypnotic use prior to CBT-I was independently associated with lack of treatment response.

31. Morin CM, Culbert JP, Schwartz SM. Nonpharmacological interventions for insomnia: a meta-analysis of treatment efficacy. Am J Psychiatry. 1994;151(8):1172-80. https://doi.org/10.1176/ ajp.151.8.1172.

32. Lichstein KL, Johnson RS. Relaxation for insomnia and hypnotic medication use in older women. Psychol Aging. 1993;8(1):10311. https://doi.org/10.1037/0882-7974.8.1.103.

33. Ong JC, Shapiro SL, Manber R. Mindfulness meditation and cognitive behavioral therapy for insomnia: a naturalistic 12-month follow-up. Explore (NY). 2009;5(1):30-6. https:// doi.org/10.1016/j.explore.2008.10.004.

34. Wang YY, Wang F, Zheng W, Zhang L, Ng CH, Ungvari GS, et al. Mindfulness-based interventions for insomnia: a metaanalysis of randomized controlled trials. Behav Sleep Med. 2020;18(1):1-9. https://doi.org/10.1080/15402002.2018.15182 28.This meta-analysis demonstrated the efficacy and favorable adherence rate of mindfulness-based interventions for insomnia.

35. Rusch HL, Rosario M, Levison LM, Olivera A, Livingston WS, $\mathrm{Wu} \mathrm{T}$, et al. The effect of mindfulness meditation on sleep quality: a systematic review and meta-analysis of randomized controlled trials. Ann N Y Acad Sci. 2019;1445(1):5-16. https://doi. org/10.1111/nyas.13996.

36. Black DS, O'Reilly GA, Olmstead R, Breen EC, Irwin MR. Mindfulness meditation and improvement in sleep quality and daytime impairment among older adults with sleep disturbances: a randomized clinical trial. JAMA Intern Med. 2015;175(4):494-501. https://doi.org/10.1001/jamainternmed. 2014.8081

37. Bastien $\mathrm{CH}$, Vallières A, Morin CM. Validation of the Insomnia Severity Index as an outcome measure for insomnia research. Sleep Med. 2001;2(4):297-307.

38. Espie CA, Kyle SD, Hames P, Gardani M, Fleming L, Cape J. The sleep condition indicator: a clinical screening tool to 
evaluate insomnia disorder. BMJ Open. 2014;4(3). https://doi. org/10.1136/bmjopen-2013-004183.

39. Garland SN, Gehrman P, Barg FK, Xie SX, Mao JJ. CHoosing Options for Insomnia in Cancer Effectively (CHOICE): design of a patient centered comparative effectiveness trial of acupuncture and cognitive behavior therapy for insomnia. Contemp Clin Trials. 2016;47:349-55. https://doi.org/10.1016/j.cct.2016.02.010.

40. Vincent N, Lionberg C. Treatment preference and patient satisfaction in chronic insomnia. Sleep. 2001;24(4):411-7. https:// doi.org/10.1093/sleep/24.4.411.

41. Matthews EE, Arnedt JT, McCarthy MS, Cuddihy LJ, Aloia MS. Adherence to cognitive behavioral therapy for insomnia: a systematic review. Sleep Med Rev. 2013;17(6):453-64. https://doi. org/10.1016/j.smrv.2013.01.001.

42. Spielman AJ, Caruso LS, Glovinsky PB. A behavioral perspective on insomnia treatment. Psychiatr Clin North Am. 1987;10(4):541-53.

43. Smith MT, Perlis ML. Who is a candidate for cognitive-behavioral therapy for insomnia? Health Psychol. 2006;25(1):15.

44. Cox RC, Olatunji BO. Sleep in a pandemic: implications of COVID-19 for sleep through the lens of the 3P model of insomnia. American Psychologist; 2021. https://doi.org/10.1037/ amp0000850.

45. Bootzin RR. Stimulus control treatment for insomnia. Proc Am Psychol Assoc. 1972;7:395-6.

46. Spielman AJ, Saskin P, Thorpy MJ. Treatment of chronic insomnia by restriction of time in bed. Sleep. 1987;10(1):45-56.

47. Harvey AG, Bélanger L, Talbot L, Eidelman P, Beaulieu-Bonneau S, Fortier-Brochu É, et al. Comparative efficacy of behavior therapy, cognitive therapy, and cognitive behavior therapy for chronic insomnia: a randomized controlled trial. J Consult Clin Psychol. 2014;82(4):670.

48. Perlis ML, Smith MT, Benson-Jungquist C, Posner DA. The conceptual framework for CBT-I. cognitive behavioral treatment of insomnia: a session-by-session guide. Springer Science \& Business Media. 2005:7-11.

49. Lacks P, Powlishta K. Improvement following behavioral treatment for insomnia - clinical-significance, long-term maintenance, and predictors of outcome. Behav Ther. 1989;20(1):11734. https://doi.org/10.1016/S0005-7894(89)80122-4.

50. Espie CA, Inglis SJ, Harvey L. Predicting clinically significant response to cognitive behavior therapy for chronic insomnia in general medical practice: analyses of outcome data at 12 months posttreatment. J Consult Clin Psychol. 2001;69(1):58-66. https:// doi.org/10.1037//0022-006x.69.1.58.

51. Crowe SF, Stranks EK. The residual medium and long-term cognitive effects of benzodiazepine use: an updated meta-analysis. Arch Clin Neuropsychol. 2018;33(7):901-11. https://doi.org/10. 1093/arclin/acx120.

52. Stranks EK, Crowe SF. The acute cognitive effects of zopiclone, zolpidem, zaleplon, and eszopiclone: a systematic review and meta-analysis. J Clin Exp Neuropsychol. 2014;36(7):691-700. https://doi.org/10.1080/13803395.2014.928268.

53.• Bathgate CJ, Edinger JD, Krystal AD. Insomnia patients with objective short sleep duration have a blunted response to cognitive behavioral therapy for insomnia. Sleep. 2017;40(1). https:// doi.org/10.1093/sleep/zsw012. Short sleep duration objectively measured using actigraphy $(<6$ hours) predicted poor reponse to CBT-I.

54. Troxel WM, Conrad TS, Germain A, Buysse DJ. Predictors of treatment response to brief behavioral treatment of insomnia (BBTI) in older adults. J Clin Sleep Med. 2013;9(12):1281-9. https://doi.org/10.5664/jcsm.3270.

55.• Bothelius K, Kyhle K, Broman JE, Gordh T, Fredrikson M. Initial sleep time predicts success in manual-guided cognitive behavioral therapy for insomnia. Behav Sleep Med.
2016;14(4):378-88. https://doi.org/10.1080/15402002.2015. 1007995. Out of several variables tested, long sleep duration was the only significant predictor of response to manualguided CBT-I delivered by non-expert primary-care personnel, a low-end treatment step requiring less resources.

56. Rochefort A, Jarrin DC, Belanger L, Ivers H, Morin CM. Insomnia treatment response as a function of objectively measured sleep duration. Sleep Med. 2019;56:135-44. https://doi.org/10. 1016/j.sleep.2019.01.016.

57. Galbiati A, Sforza M, Poletti M, Verga L, Zucconi M, FeriniStrambi L, et al. Insomnia patients with subjective short total sleep time have a boosted response to cognitive behavioral therapy for insomnia despite residual symptoms. Behav Sleep Med. 2020;18(1):58-67. https://doi.org/10.1080/15402002.2018. 1545650 .

58.• Morin CM, Edinger JD, Beaulieu-Bonneau S, Ivers H, Krystal AD, Guay B, et al. Effectiveness of sequential psychological and medication therapies for insomnia disorder: a randomized clinical trial. JAMA Psychiatry. 2020. https://doi.org/10.1001/ jamapsychiatry.2020.1767 Psychiatric comorbidity predicted less favorable treatment outcome in this study of sequential psychological and medication therapies, which suggests that insomnia treatments should incorporate a therapeutic component that addresses mood and anxiety symptoms in the presence of such symptoms.

59. Sabaté E. Adherence to long-term therapies: evidence for action. World Health Organization; 2003.

60. Matthews EE, Schmiege SJ, Cook PF, Berger AM, Aloia MS Adherence to cognitive behavioral therapy for insomnia (CBTI) among women following primary breast cancer treatment: a pilot study. Behav Sleep Med. 2012;10(3):217-29. https://doi.org/10. 1080/15402002.2012.666220.

61. Ong JC, Kuo TF, Manber R. Who is at risk for dropout from group cognitive-behavior therapy for insomnia? J Psychosom Res. 2008;64(4):419-25. https://doi.org/10.1016/j.jpsychores. 2007.10.009.

62. Cui R, Fiske A. Predictors of treatment attendance and adherence to treatment recommendations among individuals receiving Cognitive Behavioral Therapy for Insomnia. Cogn Behav Ther. 2020;49(2):113-9. https://doi.org/10.1080/16506073.2019. 1586992.Anxeity and depression symptoms predicted less attendance to CBT-I sessions and less adherence to CBT-I recommendations.

63. Yeung WF, Chung KF, Ho FY, Ho LM. Predictors of dropout from internet-based self-help cognitive behavioral therapy for insomnia. Behav Res Ther. 2015;73:19-24. https://doi.org/10. 1016/j.brat.2015.07.008.

64. Perlis M, Aloia M, Millikan A, Boehmler J, Smith M, Greenblatt $\mathrm{D}$, et al. Behavioral treatment of insomnia: a clinical case series study. J Behav Med. 2000;23(2):149-61. https://doi.org/ 10.1023/a:1005413117932.

65. Funderburk JS, Shepardson RL, Krenek M. Brief behavioral interventions for symptoms of depression and insomnia in university primary care. J Am Coll Health. 2015;63(6):398-402. https://doi.org/10.1080/07448481.2015.1015031.

66. Morin CM, Vallieres A, Guay B, Ivers H, Savard J, Merette C, et al. Cognitive behavioral therapy, singly and combined with medication, for persistent insomnia: a randomized controlled trial. JAMA. 2009;301(19):2005-15. https://doi.org/10.1001/ jama.2009.682.

Publisher's Note Springer Nature remains neutral with regard to jurisdictional claims in published maps and institutional affiliations. 